\title{
Tobacco Use and Oral Leukoplakia: Cross-sectional Study among the Gond Tribe in Madhya Pradesh
}

\author{
Surendra Kumar*, Malaisamy Muniyandi
}

\begin{abstract}
Background: Leukoplakia is an asymptomatic and potentially malignant change in the oral mucosa and high frequencies have been reported among smokers. The present study concerned the prevalence of tobacco use and leukoplakia and also associations between the two. Study design: This cross sectional survey was conducted amongst the Gond tribal population of Kundam Block, Jabalpur district, Madhya Pradesh state, Central India during 2007 to 2009. Screening for leukoplakia was conducted by a medical officer with two mouth mirrors. It is only based on visual inspection and oral pathology was not performed. A semi-structured questionnaire was used to collect information on socio-demographic and smoking habits. Prevalence of leukoplakia among users and non-users of tobacco was calculated in terms of percentages. Results: Of 1,552 individuals aged more than 12 years of age who were screened, $144(9.3 \%)$ were found to have oral leukoplakia. The prevalence of leukoplakia was significantly elevated among tobacco users as compared to non-users (11\% vs $2.5 \%$; $p<0.001)$. The percentage of leukoplakia was almost similar in both tobacco smokers and chewers $(9 \%$ vs $11 \%$; $p=0.304)$. However, the percentage of leukoplakia was especially high among those chewers who also smoked tobacco (21.9\%). Conclusions: The findings of the present study showed a positive effect of tobacco use and prevalence of leukoplakia. Also the prevalence was very high among Gond tribe, a marginalized population living in central India. There is a need for effective screening and treatment of leukoplakia in this area.
\end{abstract}

Keywords: Tobacco use - Leukoplakia - tribe - marginalized population - India

Asian Pac J Cancer Prev, 16 (4), 1515-1518

\section{Introduction}

Tobacco consumption or exposure to tobacco is an important risk factor for multiple human carcinogenic including lung cancer and those related to oral cavity and pharynx, esophagus, pancreas, liver, bladder, and cervix (World Health Organization, 2004). Tobacco use causes more than 5 million deaths worldwide per year, and current trends show that tobacco use will cause more than 8 million deaths annually by 2030 (World Health Organization, 2008). Tobacco chewing is in practice mostly in developing countries, especially those in SouthEast Asia. Tobacco chewing and smoking have been identified as major risk factors for oral cavity pre-cancer and cancer in India (Reddy et al., 2004). Bidis, a slim, handrolled, unfiltered inexpensive locally produced product, are more commonly smoked than cigarettes in rural areas and among groups of lower socio-economic status (IIPS 2010; Agrawal et al., 2013). Tobacco consumption has been found to be higher among the people of lower socio-economic groups, particularly in tribals (52.1\%) (Zahiruddin et al., 2011) and among adolescent males $(65.3 \%)$ (Dhekale et al., 2011). The epidemic of tobacco consumption is a growing phenomenon among tribal population in India.
The products used for smokeless tobacco consumption (chewing) are a big risk factor for oral cancers that cause substantial morbidity and mortality (Critchley et al., 2003). It ranks the third in top three types of cancers in India (Cocelho, 2012). Smokers in this area were using bidi (it is made by rolling a dried, rectangular piece of temburni leaf (Diospyros melonoxylon) with $0.5-0.25 \mathrm{~g}$ of sun-dried, flaked tobacco into a conical shape and securing the roll with thread) (Reddy et al., 2004) and most chewers were using gutka. It is a mixture of areca nut, slaked lime and tobacco.

Leukoplakia is an asymptomatic and potentially malignant change in the oral mucosa. Leukoplakia can be defined as a white patch or plaque that cannot be characterised clinically or pathologically like any other disease. A 10 year follow-up study conducted in India reported that oral leukoplakia preceded oral cancer in about $70 \%$ of cancer cases (Gupta et al., 1992). A high frequency of oral leukoplakia has been reported among Baiga tribe in central India (Khanna, 2012).

The National Institute for Research in Tribal Health (NIRTH), ICMR, Jabalpur, Madhya Pradesh has undertaken a series of studies to estimate the magnitude of tribal health problems and to suggest measures to improve their health conditions. A community survey 


\section{Surendra Kumar}

was conducted by the NIRTH to estimate the prevalence of tobacco use among the Gond tribe (aged more than 6 years) had shown that $65 \%$ using tobacco. Tobacco was used mainly in the forms of bidi and gutka (Kumar et al., 2013). The study revealed that tobacco consumption starts at the age of six and increases with the consumers' age. A study on KAP among school going children was done in neighboring state Chhattisgarh reported that $20.4 \%$ used tobacco (Tiwari et al., 2014a). Further to these evidences, in the current communication we report the prevalence of tobacco use and of leukoplakia and its association with tobacco use among the Gond tribe, a marginalized population living in the Kundam Block, Jabalpur district of Madhya Pradesh state in central India.

This cross sectional survey was conducted during 2007 to 2009 with the objective of estimating the prevalence of tobacco use among them as well as tobacco related morbidity.

\section{Materials and Methods}

The survey was done using individual interviews (already reported) and to estimate their tobacco related morbidity, through clinical examination. The inclusion criteria used were: persons aged 12 years and above; available at the time of survey; and willing to give written consent. As a part of this morbidity survey, screening for leukoplakia was also done by medical officer by two mouth mirrors. It is only based on visual inspection and oral pathology was not done. This was an unique opportunity to estimate the prevalence of leukoplakia in this marginalized population.

A semi-structured, pre-coded questionnaire was used to collect information. The cluster sampling procedure was adopted for sampling and required sample population was estimated by considering the expected prevalence of tobacco use as $28.5 \%$. The estimated sample size was around 1000 households assuming an average family size of four members in a household covering 4000 population. To get the representative sample from all the villages, the block was distributed into four zones like east, west, north and south. A two-stage sampling procedure was adopted for selection of clusters within the stratum. From each zone total villages were listed, at the first stage, a sample of 6-7 villages was selected by systematic sampling in each zones. In each village 50 households were selected systematically. Trained field investigators conducted the interviews after obtaining the informed consent from the head of the households or other responsible person who were able to answer their questions. The interviews were conducted at their home having informed them the purpose of the study. Respondents were told about the confidentiality of the data collected from them and also about their right to withdraw from the study at any time. The interview included information related to household identification, their demographic and socio-economic characteristics and individual tobacco consumption. A general morbidity survey was conducted by the medical officer. For this, individuals more than 12 years of age, those who are available at their residence at the time of investigation and willing to give written consent were included. Information regarding oral cavity screening was done by medical officers by means of two mouth mirrors. The presence and location of leukoplakia was also examined by using the criteria of a leukoplakia lesion with more than two different oral sites, which is most frequently found in the gingiva, alveolar processes and palate. All these identified cases were provided counseling to quit tobacco consumption, treated with basic medicines and referred to the nearest health facility/Medical College Hospital, Jabalpur for further care and management. Data were entered, checked and corrected for inconsistencies and then analyzed using the SPSS version 15.0 (SPSS Inc., Chicago, IL, USA). Prevalence of leukoplakia among users and non-users of tobacco was calculated in terms of percentages.

This study was approved by Scientific Advisory Committee and Institutional Ethics Committee of National Institute for Research in Tribal Heath (ICMR), Jabalpur.

\section{Results}

A total of 1021 households, covering the population of 4542 subjects aged 6 to 84 years were included for the tobacco survey. Among these individuals, 2970 $(65 \%)$ consumed tobacco in one form or another (Table 1). Further, 1232 tobacco users and 320 non-users were medically examined to estimate the tobacco related morbidity. Children less than 12 years of age were not included for general morbidity survey. The coverage of this survey among children aged $12-14$ years was $10 \%$ and among youths aged 15-24 was 13\%. In all 1552 subjects aged 12-84 years were examined for tobacco related morbidity. The reasons for low coverage were: unwilling to participate (those who were not facing any health problem); non availability during the survey (occupation, schooling and college); and unwilling to give written consent (Figure 1). Among tobacco consumers, $52 \%$ (639) and among non-smokers, 36\% (116) subjects were found to suffer from some kind of health ailments. The same population was also screened for leukoplakia. Overall the following number of cases were observed: Sub Mucus Fibrosis=82; COPD=92; Hypertension=292; Oral Ulcer=43; Oral Growth=3; Dental carries $=82$ and Dental Staining $=32$.

Of 1552 individuals screened, 144 (9.3\%) were found to have oral leukoplakia. The majority $(64 \%)$ of leukoplakia cases occurred in the age group of 26 to 50 years.

Another salient finding of the present study is that $(n=136) 11 \%$ of tobacco users and $(n=8) 2.5 \%$ of nonusers (never used) of tobacco were found to have oral leukoplakia (OR 4.8; $\mathrm{p}<0.001$ ). The percentage of leukoplakia was almost similar in both tobacco smokers and chewers (9\% vs $11 \%$; $=0.304$ ). However, the percentage of leukoplakia was high among those chewers who also smoked tobacco (21.9\%).

The socio-demographic characteristics of the leukoplakia cases in the present study are given in Table 2. The distribution of leukoplakia was $50 \%$ among both literate and illiterates, and $52 \%$ were males and $90 \%$ were working as labourers. The age of leukoplakia cases ranged 
Table 1. Distribution of the Study Population According to Tobacco Use and Socio-demographic Characteristics, the Gond Population in Kundam Block of Jabalpur District, Madhya Pradesh during 2007 to 2009.

\begin{tabular}{|c|c|c|c|c|c|c|c|c|c|c|c|c|}
\hline & & \multirow{2}{*}{$\begin{array}{c}\text { Total } \\
\text { population } \\
\text { No. }\end{array}$} & \multicolumn{2}{|c|}{$\begin{array}{c}\text { Non-users of } \\
\text { tobacco }\end{array}$} & \multicolumn{2}{|c|}{$\begin{array}{c}\text { Tobacco } \\
\text { users }\end{array}$} & \multicolumn{2}{|c|}{$\begin{array}{c}\text { Smoking } \\
\text { tobacco }\end{array}$} & \multicolumn{2}{|c|}{$\begin{array}{l}\text { Chewing } \\
\text { tobacco }\end{array}$} & \multicolumn{2}{|c|}{ Mixed users } \\
\hline & & & No. & $\%$ & No. & $\%$ & No. & $\%$ & No. & $\%$ & No. & $\%$ \\
\hline \multirow[t]{2}{*}{ Occupation } & Labour & 2994 & 615 & 20.5 & 2379 & 79.5 & 625 & 20.9 & 1618 & 54 & 136 & 4.5 \\
\hline & Others & 1548 & 957 & 61.8 & 591 & 38.2 & 56 & 3.6 & 516 & 33.3 & 19 & 1.2 \\
\hline \multirow[t]{2}{*}{ Sex } & Male & 2272 & 679 & 29.9 & 1593 & 70.1 & 641 & 28.2 & 805 & 35.4 & 147 & 6.5 \\
\hline & Female & 2270 & 893 & 39.3 & 1377 & 60.7 & 40 & 1.8 & 1329 & 58.5 & 8 & 0.4 \\
\hline \multirow[t]{2}{*}{ Education } & Illiterate & 1881 & 605 & 32.2 & 1276 & 67.8 & 354 & 18.8 & 863 & 45.9 & 59 & 3.1 \\
\hline & Literate & 2661 & 967 & 36.3 & 1694 & 63.7 & 327 & 12.3 & 1271 & 47.8 & 96 & 3.6 \\
\hline \multirow[t]{3}{*}{ Age } & $\leq 35$ & 2807 & 1168 & 41.6 & 1639 & 58.4 & 154 & 5.5 & 1417 & 50.5 & 68 & 2.4 \\
\hline & $>35$ & 1735 & 404 & 23.3 & 1331 & 76.7 & 527 & 30.4 & 717 & 41.3 & 87 & 5 \\
\hline & & 4542 & 1572 & 34.6 & 2970 & 65.4 & 681 & 15 & 2134 & 47 & 155 & 3.4 \\
\hline
\end{tabular}

Table 2. Distribution of Leukoplakia Cases According to their Demographic and Socio-economic Status and Type of Tobacco Use, among the Gond population in Kundam Block of Jabalpur District, Madhya Pradesh (Aged >12 Years) during 2007 to 2009

\begin{tabular}{|c|c|c|c|c|c|c|c|c|c|c|c|c|c|c|}
\hline & & \multirow{3}{*}{$\begin{array}{l}\text { Total } \\
\text { No. }\end{array}$} & \multirow{2}{*}{\multicolumn{4}{|c|}{$\begin{array}{l}\text { Non-users of } \\
\text { tobacco }\end{array}$}} & \multirow{2}{*}{\multicolumn{2}{|c|}{ Tobacco users }} & \multicolumn{6}{|c|}{ Type of tobacco used } \\
\hline & & & & & & & & & \multicolumn{2}{|c|}{ Smokers } & \multicolumn{2}{|c|}{ Chewers } & \multicolumn{2}{|c|}{ Mixed users } \\
\hline & & & No. & $\%$ & No. & $\%$ & No. & $\%$ & No. & $\%$ & No. & $\%$ & No. & $\%$ \\
\hline \multirow[t]{2}{*}{ Sex } & Male & 737 & 75 & 10 & 2 & 0.3 & 73 & 9.9 & 32 & 4.3 & 33 & 4.5 & 8 & 1.1 \\
\hline & Female & 815 & 69 & 8 & 6 & 0.7 & 63 & 7.7 & 0 & 0 & 62 & 7.6 & 1 & 0.1 \\
\hline \multirow[t]{2}{*}{ Age } & $\leq 35$ & 644 & 78 & 12 & 3 & 0.5 & 75 & 11.6 & 14 & 2.2 & 59 & 9.2 & 2 & 0.3 \\
\hline & $>35$ & 908 & 66 & 7 & 5 & 0.6 & 61 & 6.7 & 18 & 2 & 36 & 4 & 7 & 0.8 \\
\hline \multirow[t]{2}{*}{ Education } & Illiterate & 833 & 72 & 9 & 5 & 0.6 & 67 & 8 & 18 & 2.2 & 46 & 5.5 & 3 & 0.4 \\
\hline & Literate & 719 & 72 & 10 & 3 & 0.4 & 69 & 9.6 & 14 & 1.9 & 49 & 6.8 & 6 & 0.8 \\
\hline \multicolumn{2}{|c|}{ OccupationLabour } & 1318 & 129 & 10 & 6 & 0.5 & 123 & 9.3 & 31 & 2.4 & 83 & 6.3 & 9 & 0.7 \\
\hline \multirow{2}{*}{\multicolumn{2}{|c|}{ Total }} & 234 & 15 & 6 & 2 & 0.9 & 13 & 5.6 & 1 & 0.4 & 12 & 5.1 & 0 & 0 \\
\hline & & 1552 & 144 & 9 & 8 & 0.5 & 136 & 8.8 & 32 & 2.1 & 95 & 6.1 & 9 & 0.6 \\
\hline
\end{tabular}

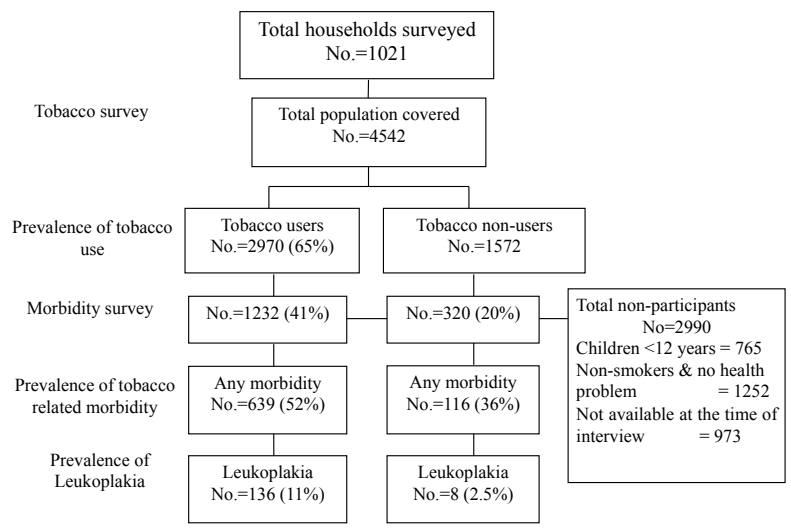

Figure 1. Profile of Study Population in Reference to Tobacco Consumption

from people of 12 to 84 years of age and $54 \%$ were found to be in the age group of $<35$ years.

\section{Discussion}

The health consequences of smokeless tobacco consumption have been studied extensively which clearly demonstrated its causal role in oral cancer (International Agency for Research on Cancer, 1984). This was also shown by the study of Pindborg et al. which reported 69\% of leukoplakia cases were among bidi smokers (Pindborg et al., 1967).

The prevalence of leukoplakia in present study population was very high as compared to earlier studies reported from other parts of India, according to which prevalence of leukoplakia was 3.3\% in Lucknow; $1.6 \%$ in Bangalore, 2.8\% in Bombay and 6.5\% in Madhya Pradesh (Gupta et al., 1992; Dhekale et al., 2011). All these studies had been conducted on non-tribal populations whereas the present study was concentrated on a population of a disadvantaged tribal group living in very backward area. It was corroborated with study done among the same tribe (Baiga) living in Manpur block, central India, 25\% developed leukplakia among tobacco users as compared to 0.4\% among non-users (Khanna, 2012). High prevalence of leukoplakia may be partly due to the poor economic status of the subjects of the present study as majority of them (96\%) live in katcha houses (made of poor quality materials) and work as daily wage labours. High prevalence may also be due to refusal for screening among persons with no symptoms.

In this study, among 839 individuals, who chewed tobacco $65(7.7 \%)$ had oral sub-mucous fibrous disease, a pre-cancerous condition. It was also reported by dental practitioners and researchers that a rapid increase in the incidence of oral sub-mucous fibrosis, a chronic debilitating disease with no known cure, is caused by chewing areca nut, often mixed with tobacco generally called as gutkha (Sinor et al., 1990). Also by Tiwari et al., reported that very high calculus formation $(\mathrm{OR}=14.3)$ amongst school going children involved in consuming gutkha (Tiwari et al., 2014a).

Considerable social science research has been carried 
out among non-tribal population (Gupta et al., 1986) and some special groups like prisoners (Tiwari et al., 2014b) to assess why people begin consuming tobacco, why they continue it, what they perceive as the health effects of using tobacco, and what influences could help them discontinue its use. Similar studies need to be done in other tribal areas as well, and to educate the tribal population about the health risks of smoking and smokeless tobacco use. Such efforts may significantly help this marginalized population to improve their health status.

Till date, there is no evidence of effective treatment or prevention of malignant transformation of leukoplakia apart from avoiding or quitting tobacco use (Kumar et al., 2013). Treatments may be effective in the resolution of lesions, but relapses and adverse effects are common. So irrespective of response to therapy, long-term follow-up is essential for early identification of cancer for timely treatment. Presently there is no controlled clinical trial testing of surgical treatment for leukoplakia and also surgical treatment does not assure prevention of recurrence. Identification of cancers in their initial stages by histopathological investigations under field conditions particularly in tribal areas is very difficult.

In conclusion, this study indicates that prevalence of oral leukoplakia is significantly high among tobacco smokers and chewers as compared to non tobacco users in this population. Finding of this study are also consistent with studies done in other geographical non-tribals areas in India. This evidence points to the critical importance in early cancer detection of screening for leukoplakia. Therefore, an effective screening of population and treatment of leukoplakia is needed wherever tobacco consumption is common.

\section{Acknowledgements}

We sincerely thank Director General, Indian Council of Medical Research (ICMR), New Delhi for his encouragement and constant support. We are grateful to Dr. Neeru Singh, Director, National Institute for Research in Tribal Health (ICMR), Jabalpur for her permission, encouragement, co-operation and continuous support. We thank the Block Medical Officer of Kundom Block for his cooperation. We also thank and acknowledge the project team members for their support on data collection, cleaning and entry. We also thank all the respondents for their co-operation for the interview. We sincerely thank the ICMR for providing financial support for this study.

\section{References}

Agrawal S, Karan A, Selvaraj S, et al (2013). Socio-economic patterning of tobacco use in Indian states. Int J Tuberc Lung Dis, 17, 1110-7.

Cocelho KR (2012). Challenges of the oral cancer Burden in India. J Cancer Epidemiol, 2012:701932.

Critchley JA, Unal B (2003). Health effects associated with smokeless tobacco: a systematic review. Thorax, 58,435-43.

Dhekale DN, Gadekar RD, Kolhe CG (2011). Prevalence of tobacco consumption among the adolescents of the tribal areas in Maharashtra. J Clinical Diagnostic Res, 5, 1060-3.

Gupta PC, Mehta FS, Pindborg JJ, et al (1986). Intervention study for primary prevention of oral cancer among 36,000 Indian tobacco users. Lancet, 1, 1235-8.

Gupta PC, Mehta FS, Pindborg JJ, et al (1992). Primary prevention trial of oral cancer in India: a 10 year follow up study. J Oral Pathol Med, 21, 433-9.

International Agency for Research on Cancer (1984). IARC monographs on the evaluation of the carcinogenic risk of chemicals to humans: tobacco habits other than smoking; betel-quid and areca-nut chewing; and some related nitrosamines (Vo. 37). Lyon: IARC.

International Institute for Population Sciences \& Ministry of Health and Family Welfare, Government of India (2010). Global adult tobacco survey, India 2009-10. IIPS; Mumbai, India.

Khanna S (2012). The interaction between tobacco use and oral health among tribes in central India. Tobacco Induced Diseases, 10, 16-7.

Kumar A, Cascarini L, McCaul JA, et al (2013). How should we manage oral leukoplakia? Br J Oral Maxillofac Surg, $\mathbf{5 1}, 377-83$.

Kumar S, Kumar D, Muniyandi M, et al (2013). Poverty does not limit tobacco consumption among tribal population: Evidence from central India. Asian Pac J Cancer Prev, 14, 6195-6.

Pindborg JJ, Joyce K, Gupta PC, et al (1967). Studies in oral leukoplakias: prevalence of leukoplakia among 10000 persons in Lucknow, India, with special reference to use of tobacco and betel nut. Bull Wid Hlthi Org, 37, 109-16.

Reddy KS, Gupta PC (2004). Report on tobacco control in India. Ministry of Health and Family Welfare, Government of India, New Delhi.

Sinor PN, Gupta PC, Bhonsle RB, et al (1990). A case control study of oral submucous fibrosis with special reference to the etiologic role of areca nut. J Oral Pathol Med, 19, 94-8.

Tiwari RV, Megalamanegowdru J, Gupta A, et al (2014a). Knowledge, attitude and practice of tobacco use and its impact on oral health status of 12 and 15 year-old school children of Chhattisgarh, India. Asian Pac J Cancer Prev, 15, 10129-5.

Tiwari RV, Megalamanegowdru J, Parakh A, et al (2014b). Prisoners' perception of tobacco use and cessation in Chhattisgarh, India-the truth from behind the bars. Asian Pac J Cancer Prev, 15, 413-7.

World Health Organization (2004). IARC Monographs on the evaluation of carcinogenic risks to humans. World Health Organization, International Agency for Research On Cancer, Lyon, France, $83 \& 89$.

World Health Organization (2008). WHO report on the global tobacco epidemic 2008. Geneva: World Health Organization [Accessed Jan 2015].

Zahiruddin QS, Gaidhane A, Bawankule S, et al (2011). Prevalence and pattern of tobacco use among tribal adolescents: Are tobacco prevention messages reaching the tribal people in India? Ann Trop Med Public Health, 4, 74-80. 